\title{
Social Media among Thai students: Narcissism, self-identity or empowerment?
}

\author{
Yuwanuch Gulatee $^{1}$, Babara Combes $^{2} \&$ Yuwadee Yoosabai ${ }^{3}$ \\ ${ }^{1}$ School of Management and Information Technology, Nakhonphanom University, Nakhonphanom, Thailand \\ ${ }^{2}$ School of Information Studies Charles Sturt University, Australia \\ ${ }^{3}$ English Language Teaching Department, Panyapiwat Institute of Management, Bangkok, Thailand \\ Correspondence: Yuwanuch Gulatee, School of Management and Information Technology, Nakhonphanom \\ University, Nakhonphanom, Thailand. Tel: 66-42-587-288. E-mail: ygulatee@ npu.ac.th, ygulatee@gmail.com
}

Received: November 24, 2020

Accepted: December 22, 2020 Online Published: January 5, 2020

doi:10.5539/hes.v11n1p79

URL: https://doi.org/10.5539/hes.v11n1p79

\begin{abstract}
Background: Social media has now become a ubiquitous part of everyday life, especially for young people. This technology is a double-edged sword and can be used to empower or isolate users. This research is designed to enhance our understanding of how social media is being used by young people, how it affects them and their attitudes towards it.

Results: This paper reports on the findings of a follow-up study to explore student feelings and attitudes and student preferences and self-perceptions when using technology. Earlier research examined emerging trends and changes in how students and staff use technology for learning and teaching and ownership of technology. This part of the long-term research project explored student attitudes and self-perceptions when using social media for personal use. Findings confirmed that there is a high use of Facebook amongst the young people in this study and their attitudes toward social media are more positive than negative. Participants felt that social media helped them to communicate with people from around the world, was easy to use for communication and could be used anywhere and at any time. They used social media most often to communicate with friends, colleagues, family and significant others, rather than people they did not know personally. However, they did use social media to build an online presence or profile and used this online platform to raise their status and for self-promotion to the wider community. Participants also admitted that social media impaired concentration, listening and completing activities in the classroom and sometimes caused personal relationship problems. A mobile phone is the device they use most often to access social media. Results also indicate that young people using social media in Thailand do not have a high level of concern about third-party access to their data. However, results from the study do not clearly show that using social media affects the ability of young people to communicate face-to-face.

Conclusion: The widespread use of Facebook amongst the Thai students taking part in this study was found to have both positive and negative effects on their communication, entertainment, academic and social lives, their sense of self and personal empowerment.
\end{abstract}

Keywords: social media, self-identity, empowerment, consequences of using ICT

\section{Introduction}

\subsection{Introduce the Problem}

The use of social media platforms is widely popular in Thailand, particularly amongst young people, with Facebook ranked as the leading social media platform. In Southeast Asia, Thailand can even be counted among the leading social media countries. Thailand has used social media for emerging marketing in areas such as tourism and retail, where the visibility provided by social media provides greater marketing opportunities for remote businesses. Many big Thai companies and small businesses use social media not only to promote and publish their services, but also to sell their products. They use social media platforms such as Facebook to target Thai customers in Thailand and overseas, an audience estimated to be more than 50 million people (Lexicon, 2019). In 2011 more than 800 million people registered on Facebook (Suksa-ngiam\& Chaiyasoonthorn, 2015) which was an increase from 500 million in 2010 (Suksa-ngiam\& Chaiyasoonthorn, 2015). Social media sites and 
apps have also grown in high numbers with an increased use of mobile devices and approximately two billion users using social networking sites and apps in 2015. This number is likely to cross the 2.6 billion mark by 2018 (Statista, 2020b).

Social media has also played an important role as an alternative news media in Thailand. For example, during the 2011 floods, social media outlets provided ordinary people with information and communication that enabled them to cope with the floods (Wang, Tchernev, Solloway, 2012; Leong, Pan, Ractham \& Kaewkitipong, L, 2015). The increased use of social media in Thailand provides a backdrop for the main research question of this study: Is the use of social media empowering or affirming the ideal self for Thai university students? The purpose of this research on how Thai youth are using social media, is to provide a venue for critical academic research that focuses on the both the dark side and empowerment aspects of social media as perceived by young university students. The study also explores the use of social media by young people, self-awareness of the positive and negative aspects of social media, self-perception and feelings of self-empowerment. The study was conducted at one University located in the North East of Thailand and is part of an ongoing, long-term study exploring the use of technology by young people.

\subsection{Background}

By the end of the 1990s, social commentary and researchers began referring to society as digitally wired and part of the Information Age as the Internet moved from universities into the public domain (Negroponte, 1998). One of the first social networking platforms (social media) was Facebook. It was created by Harvard student Mark Zuckerberg and launched to the public domain in 2004. By the end of 2019, Facebook had more than 2.5 billion users worldwide with 2.89 billion people using Facebook and its associated products WhatsApp, Instagram, and Messenger on a monthly basis (Statistica, 2020a). For many young people, Facebook appears to have become an integral part of everyday life. Young people use Facebook to diarize and create visual logs of their lives. They also use it for communication, banking, online shopping, news gathering, and entertainment (Gulatee \& Combes, 2018). Technology appears in all levels of society from the rice field, the marketplace, the grocery store self-serve, online banking and shopping, and school classrooms. Social media has become a way of communicating, socialising, conducting business, making and maintaining social and family connections. Our lives have been changed by social media technologies. In Thailand, Gulatee \& Combes, (2018) found that half of the respondents in their research reported that they could not live without the Internet, while $62 \%$ of the Australian students reported similar findings. Throughout both the Thai and the Australian research there were no significant differences between answers from males and females. Research by Leong, Pan, Ractham, \& Kaewkitipong, (2015) found that social media also empowered people in Thailand during the 2011 Thailand flood crisis, and concluded that social media contributes to addressing social challenges and could affect social change and address public concerns, such as natural disasters. Research has also found that using Facebook influences young people by increasing positive self-belief, self-confidence, and positive thoughts and feelings. However, Social media use also significantly to fulfill emotional and cognitive needs. Social media use can improves social relationships and social capital needs. As well as, Students did not appear to understand the probable of technology to support their learning. On the other hand, they can looked to their lecturers for ideas on technology enhanced their learning (Wang, Tchernev and Solloway, 2012). As found on Margaryan, 2011, Students have limited understanding of what tools they could implement and how to support their own learning (Margaryan, 2011).Research by Alryalat, Alzubi, Rana, \& Sarma (2016) also found that participants in their study were strongly positive about social media platforms such as Facebook. Participants' felt that the usefulness and the benefits of social media was significant and enabled them to interact with friends, colleagues, the community, wider society and their study. The study of Olsson, 2016 have been very useful for the research field as first insights which found the new empirical area, to some extent reminded of interesting point of what is going on with Social network. The research found social Network is a contemporary civic and the ways in which they have become involved in different forms of politics.Isaranon $(2016$, p.4) found that 'social media facilitates agentic and communal narcissists to feel their best and move towards their ideal self, particularly when cognitive and behavioral strategies used on social media match their orientation towards goals". Therefore, this study aims to explore how young people in Thailand use social media, their understanding of the 'good and bad aspects of social media', and their attitudes, feelings and self-perception when using social media.

\subsection{Describe Relevant Scholarship}

Discuss the relevant related literature, but do not feel compelled to include an exhaustive historical account. Assume that the reader is knowledgeable about the basic problem and does not require a complete accounting of its history. A scholarly description of earlier work in the introduction provides a summary of the most recent directly related work and recognizes the priority of the work of others. Citation of and specific credit to relevant 
earlier works are signs of scientific and scholarly responsibility and are essential for the growth of a cumulative science. In the description of relevant scholarship, also inform readers whether other aspects of this study have been reported on previously and how the current use of the evidence differs from earlier uses. At the same time, cite and reference only works pertinent to the specific issue and not those that are of only tangential or general significance. When summarizing earlier works, avoid nonessential details; instead, emphasize pertinent findings, relevant methodological issues, and major conclusions. Refer the reader to general surveys or research syntheses of the topic if they are available. Demonstrate the logical continuity between previous and present work. Develop the problem with enough breadth and clarity to make it generally understood by as wide a professional audience as possible (Beck \& Sales, 2001). Do not let the goal of brevity lead you to write a statement intelligible only to the specialist.

\subsection{State Hypotheses and Their Correspondence to Research Design}

After you have introduced the problem and have developed the background material, explain your approach to solving the problem. In empirical studies, this usually involves stating your hypotheses or specific question and describing how these were derived from theory or are logically connected to previous data and argumentation. Clearly develop the rationale for each. Also, if you have some hypotheses or questions that are central to your purpose and others that are secondary or exploratory, state this prioritization. Explain how the research design permits the inferences needed to examine the hypothesis or provide estimates in answer to the question.

\section{Method}

\subsection{Participants}

Participants in this research study were students enrolled across all fields of study at a University in Thailand. The total number of students who participated in the study was 467 (61\% female and 39\% male). The data collection used accidental sampling technique (Statistics How To, 2020), and did not focus on any particular faculty or student group at the university. A diverse range of students answered the online survey and were evenly spread across fields of study and years of study in the Bachelor degree. Approximately $80 \%$ of participants were between the ages of 18-22 years. It must be noted that participants at the university were familiar with using social media tools within the context of their study at the university. University policy meant that lecturers and some students were using the social media platform Line for all communications.

\subsection{Research Instruments}

Data was collected using a questionnaire and a short, semi-structured interview to provide both quantitative and qualitative data. Qualtrics software was used to collect and analyse the quantitative data set which was collected using an online survey tool. Researchers chose to use an online questionnaire via the Internet for ease of access for the participants and to align with the technology focus of the study. Using an online survey method was also deemed to be the most effective method for gathering data from a large group of students. Students were informed of the survey via a link placed on the University website and after the student login so that they had ready access to the survey. There were twenty-four (24) questions in the questionnaire that were grouped according to the following categories: demographics and using social media (frequency of use, self-perception of the advantages and disadvantages, devices/platforms used, security issues). The questionnaire and the interview instruments were designed to clarify the participants' attitudes and knowledge about social media. Questions were close-ended, used a five-point Likert scale (included and N/A option), with respondent data fed into a common database for analysis. The questionnaire and data entry used dropdown menus and radio buttons to ensure an uncluttered layout and encourage accurate data entry. Finally, a progress bar indicated how far participants were through the questionnaire to encourage them to continue through to the end. Statistics used for data analysis were the percentage, mean and standard deviation.

The qualitative data was obtained by in-depth, semi-structured interviews. Semi-structured interviews were designed to explore in more detail how participants from the original survey used social media. The research literature supports semi-structured interviews as a useful technique for collecting in-depth data from individual participants, as it forms a framework where the interviewees can articulate and reflect upon their experiences (Pickard, 2007). In-depth, semi-structured interviewing is primarily an 'interpretive process'. It is a research method which accommodates how people interpret the world around them and assign personal meaning to events, issues and experiences (Liamputtong \& Ezzy, 1999). The length of the interviews and the semi-structured nature of the questions and probes assisted in keeping the time allocation (half an hour) consistent for the interviews, and kept to a minimum the influence of individual participants who were more garrulous or dominant. Questions were designed to obtain a more detailed picture of how young people use social media in their daily lives, and included questions about self-perception, an understanding of the good and bad aspects of social media and 
feelings of empowerment (Fieseler \& Fleck, 2013) when they post on social media platforms. Responses from the interview questions provided a wealth of qualitative data which was transcribed and coded thematically (Pickard, 2007). A number of gift phone cards were offered as an incentive for participants to return and participate in the interviews, with recipients being randomly selected using accidental sampling technique.

\subsection{Research Framework}

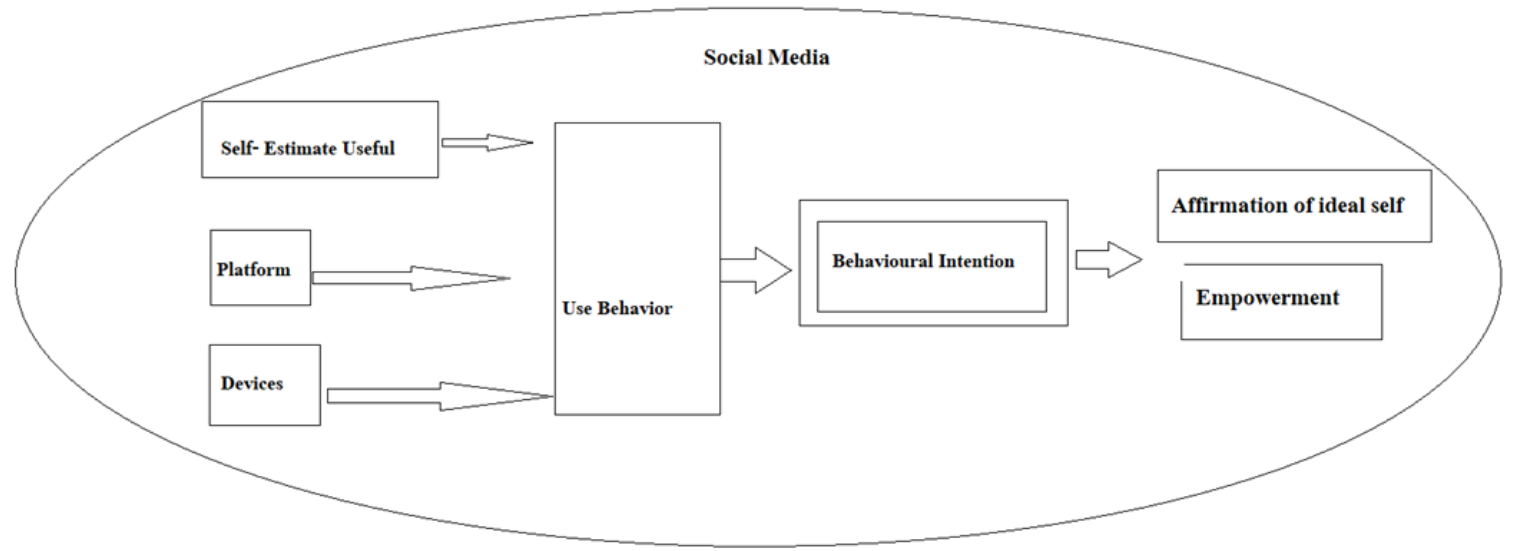

Figure 1. Research Framework

\section{Findings}

Participants in this research study were students enrolled across all fields of study in the University. Participants consisted mainly of ages from $17-25$, with a total of 467, of which 180 were male (38.54\%) and 287 were female $(61.46 \%)$. A small number were aged between $25-45$. These facts are represented graphically below in Figures 2 and 3.

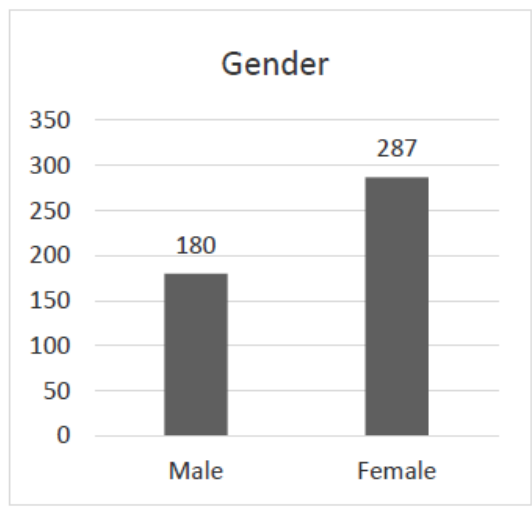

Figure 2. Gender of the participants

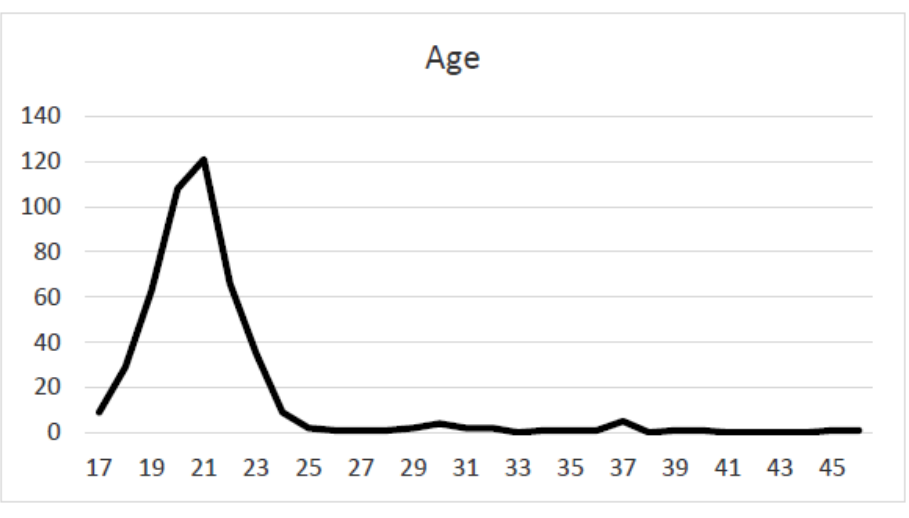

Figure 3. Age of participants

The results below indicate that approximately $80 \%$ of participants were between the ages of 19-23, and most were Bachelor degree students. However, a small number were aged between 26-45 and were Masters or PhD level students. Most of the participants were in their third year at university followed by first, second and fourth-year students. Participants were studying in a range of courses, including Liberal Arts, Education, Science, the Management Science and Industrial Technology. These results are available in Figures 4 and 5 below. 


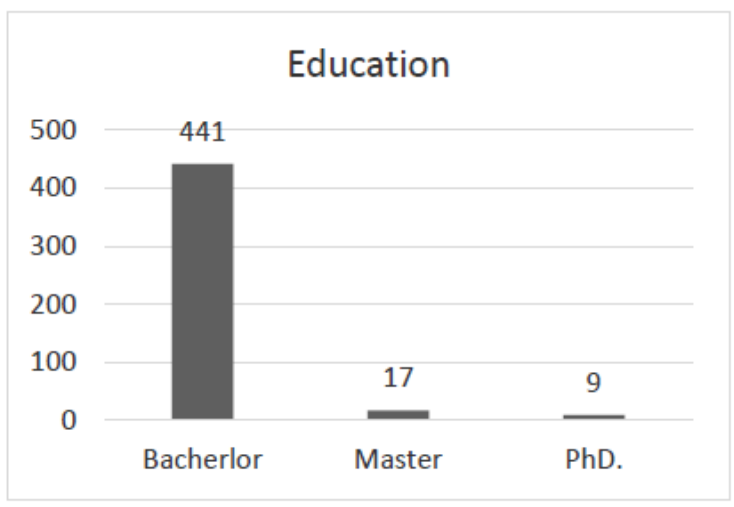

Figure 4. Education level of participants

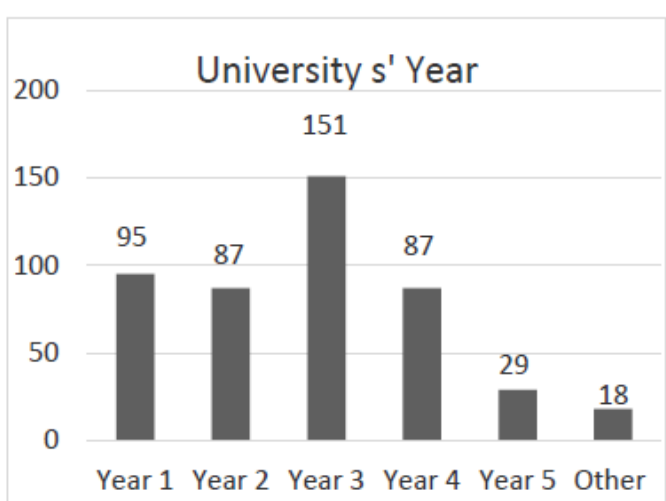

Figure 5. Year of participants

Figure 6 reveals how the participants were using social media, with more than $80 \%$ claiming they use it often and only $2 \%$ saying they are not using it. These results indicate that Thai students in this study were using social media regularly. Results from this study are very similar to results from research conducted in 2016 and 2017 (Gulatee \& Combes, 2018). Results in Figure 7 indicate that $95 \%$ of the participants felt the need to access social media every day and more than $80 \%$ access it every hour. These results show that social media is an integral part of their everyday life

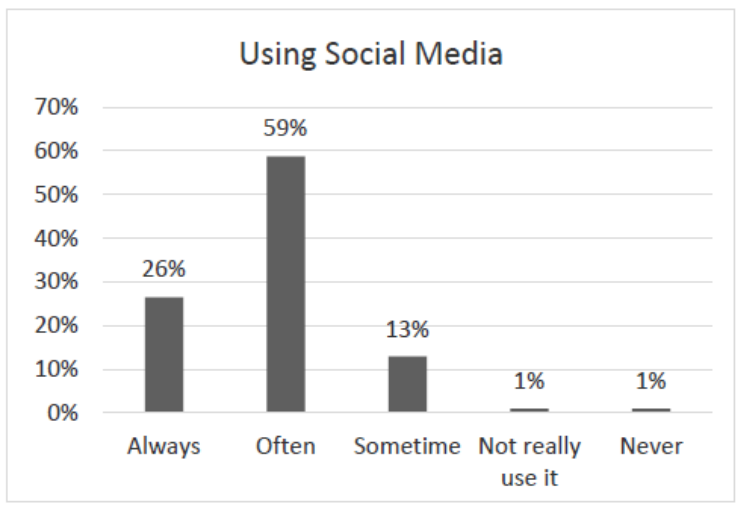

Figure 6. Using Social Media

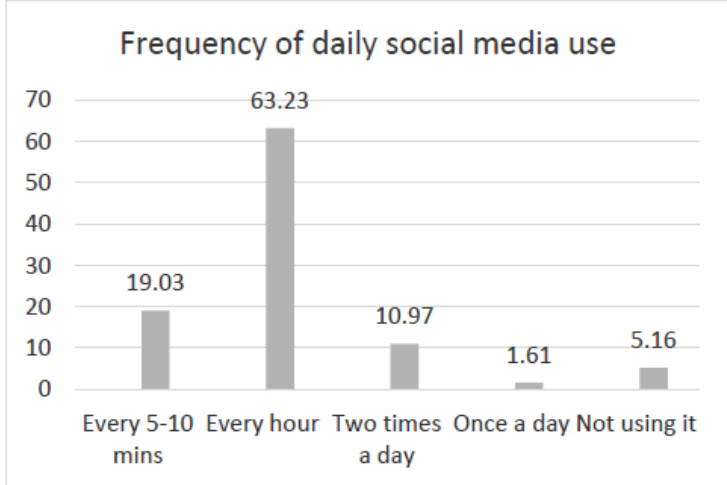

Figure 7. Frequency of daily social media use

Figure 8 indicates that Facebook (31\%), Instagram and Line $(25 \%)$ had a high penetration rate amongst participants. Statista (2020) supports these results and reports that the number of Facebook users in Thailand reached 26.9 million, up from 26.3 million in 2018-2019. Social platforms such as Facebook and Line were being accessed by close to two billion users on a monthly basis in 2019. Moreover, more than half of them were using Facebook (Statista, 2020). Some of the negative impacts recognised by the participants are shown in Figure 9. These include impaired concentration and listening in the classroom, non-participation in class activities and problems when communicating with others face-to-face. Rajesh et., al (2016, p.1) found a similar result and reported that 'the widespread use of Facebook among health science students, was found to have both positive and negative effects on their academic achievement ( Lau, 2017) social life, and health.' Additionally, a study by Makin (2018), found that digital technologies such as social media, video games and screen time in general, have been linked to impaired memory, attention deficit and reading ability, thus making users less sociable, civil and empathetic. 


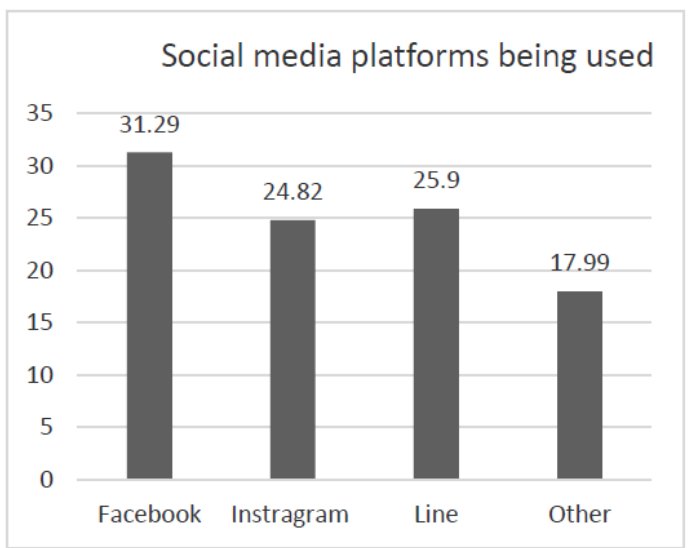

Figure 8. Social media platforms being used

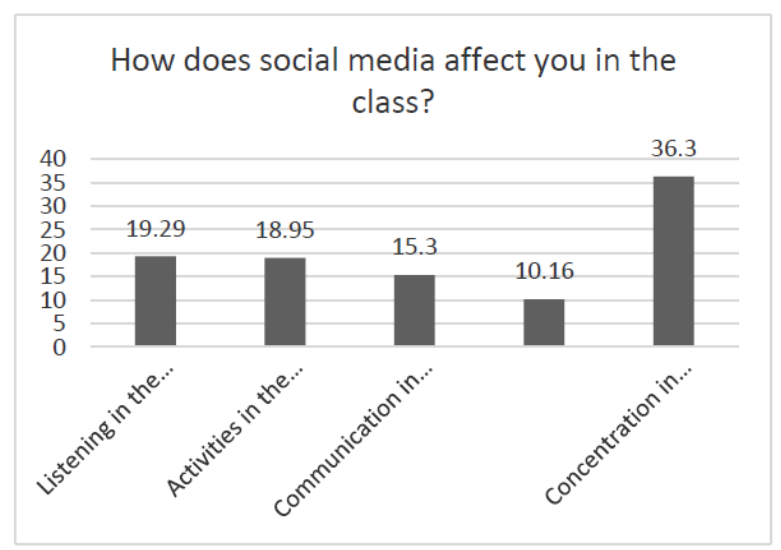

Figure 9. How does social media affect you in class?

Results in Figure 10 indicate that mobile phones were the preferred device participants were using most frequently to access social media (52\%), followed by the computer (39\%) and tablets (5\%). Statista (2020) reports that from 2017 to 2023 the number of mobile internet users are predicted to increase from 26.5 million to 32.4 million. Additionally, Gulatee, Program \& Combes (2018) found that the ownership of laptops and smartphones by Thai students had increased significantly by 2017 , while ownership of desktop computers and tablets had barely changed. This may be due to the lower cost of smartphones over computers that make smartphone ownership the preferred option for participants. They are also mobile and provide ready access for participants.

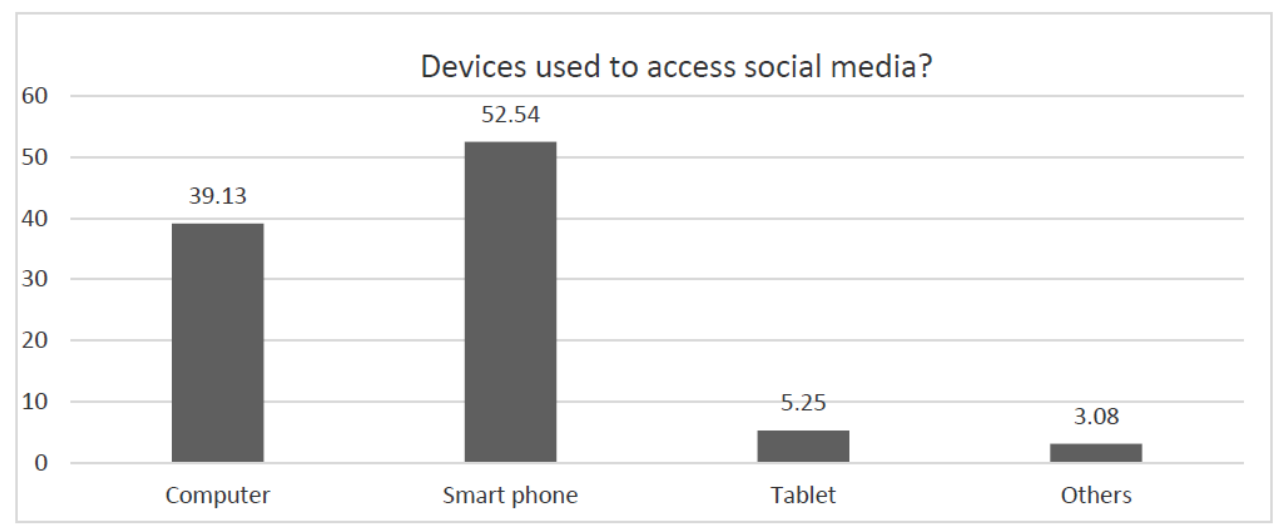

Figure 10. Devices used to access social media

Figure 11 results indicate that more than half of the participants $(53 \%)$ used Facebook for entertainment, for posting photographs everywhere they go and promoting themselves (15\%), with only $14 \%$ looking for information. Surprisingly, they were not using their device to look for academic information. Research by Richtel, (2010) indicated that young people tend to use technologies for entertainment, not learning, and overuse of technologies in the classroom can hurt school performance. 


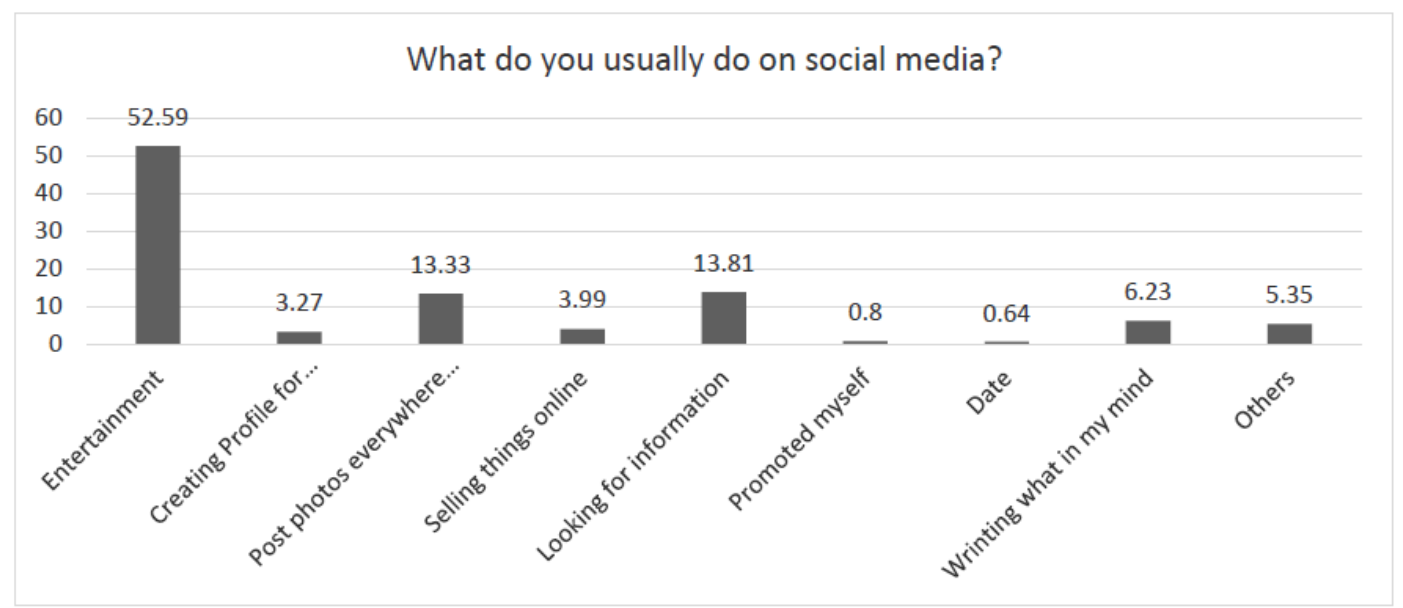

Figure 11. What do you usually do on social media?

One-third of participants in this research indicated that they allow everyone/anyone (42\%) to see their status and personal information. This result indicates that these young people on social media do not have a high level of concern about third-party access to their data. Only $2 \%$ said they were concerned. These results are below in Figure 12.

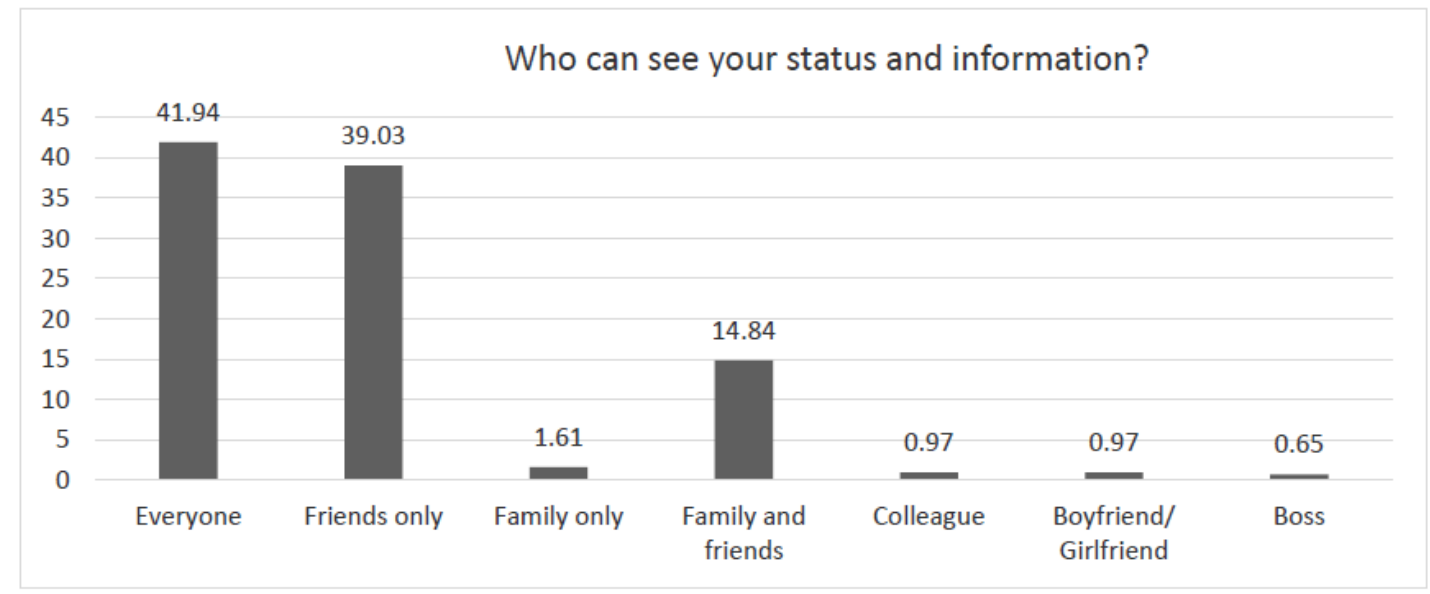

Figure 12. Who can see your status and information?

Figures 13 and 14 indicate a similar result with $85 \%$ admitting that they post photos of themselves in an attempt to make themselves look good on social media. Research by Madden et.al . (2013) found that from 2006 till $2013,91 \%$ teens posted photographs of themselves. In addition, Isaranon $(2016$, p.117) found that 'there were no differences in Facebook movement towards the ideal self and life satisfaction between communal narcissists in the self-focused and other-focused conditions, or between communal narcissists and non-narcissists in the other-focused condition'. In this research, the researcher found that users who post personal content on social media to bolster feelings of self-esteem and self-affirmation are no different to the feelings experienced when they post content that is more community orientated. She concluded that 'social media facilitates agentic and communal narcissists to feel their best and move towards their ideal self, particularly when cognitive and behavioural strategies used on social media match their orientation towards goals' (Isaranon, 2016, p.4). 


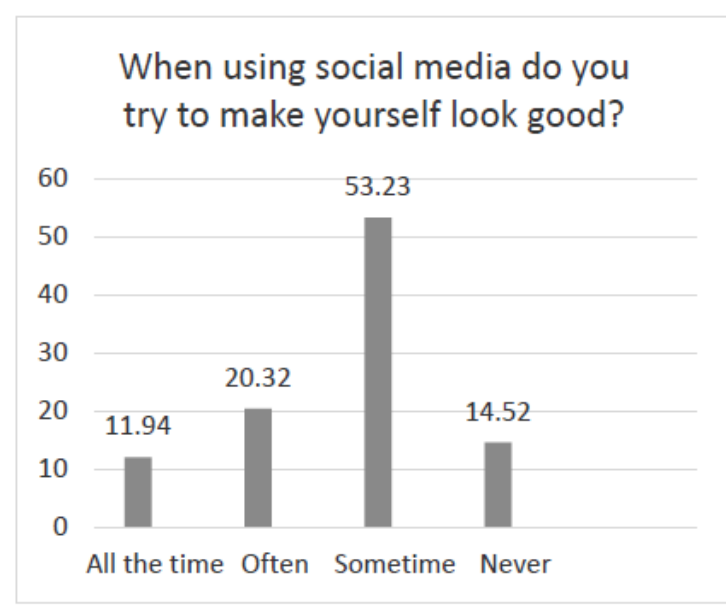

Figure 13 . When using social media do you try to make yourself look good?

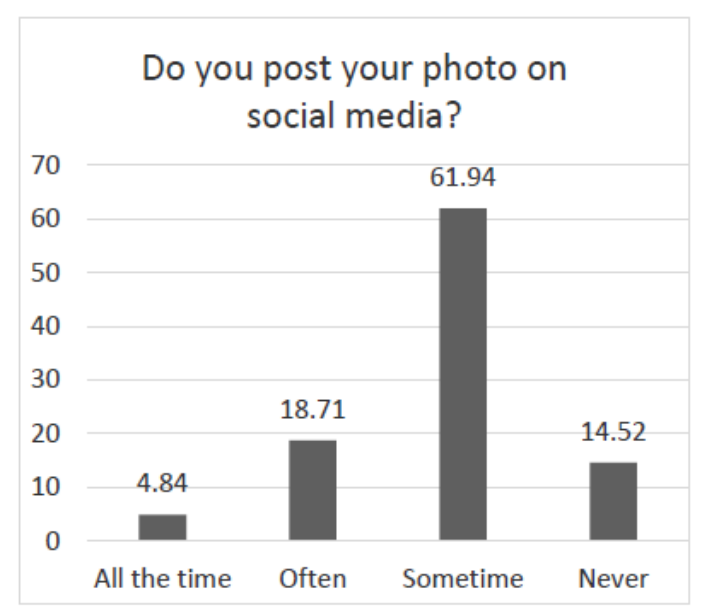

Figure 14. Do you post your photo on social media?

Figures 15 and 16 participants $(69 \%)$ reported that communicating via social media makes them feel more confident than when communicating face-to-face. Although the result in Figure 15 is not clear (half and half), it is interesting that $50 \%$ of participants felt that too much social media made their face-to-face communication skills worse.

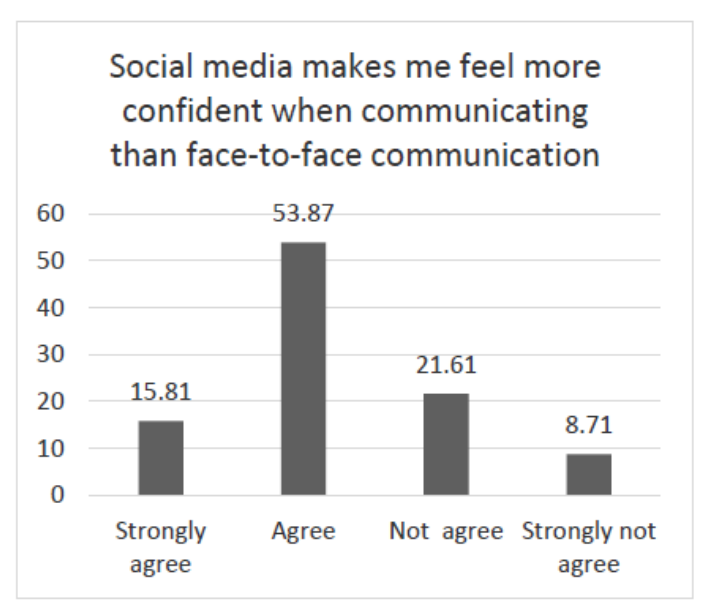

Figure 15. Social media makes me feel more confident to when communicating than F-T-F communication

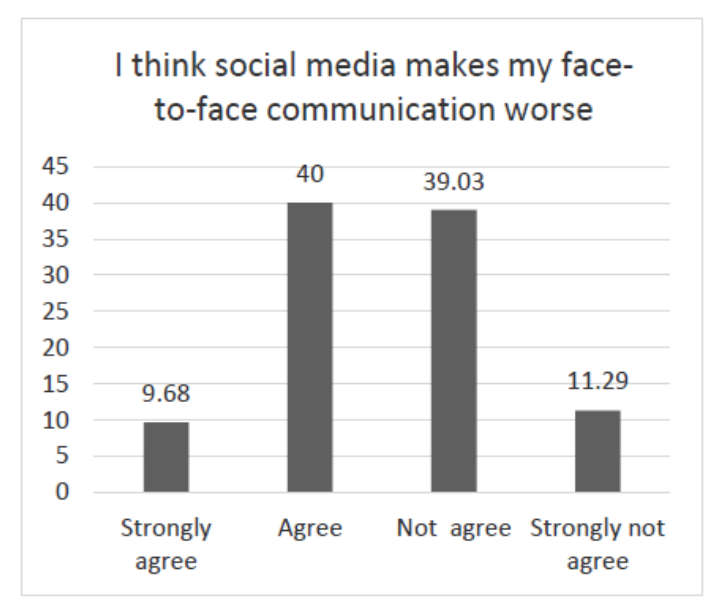

Figure 16. Social media makes my face-to-face communication worse

In Figure 17 participants reported being more positive about the use of social media as a way of helping them to communicate and associate with people around the world, and at any time. 


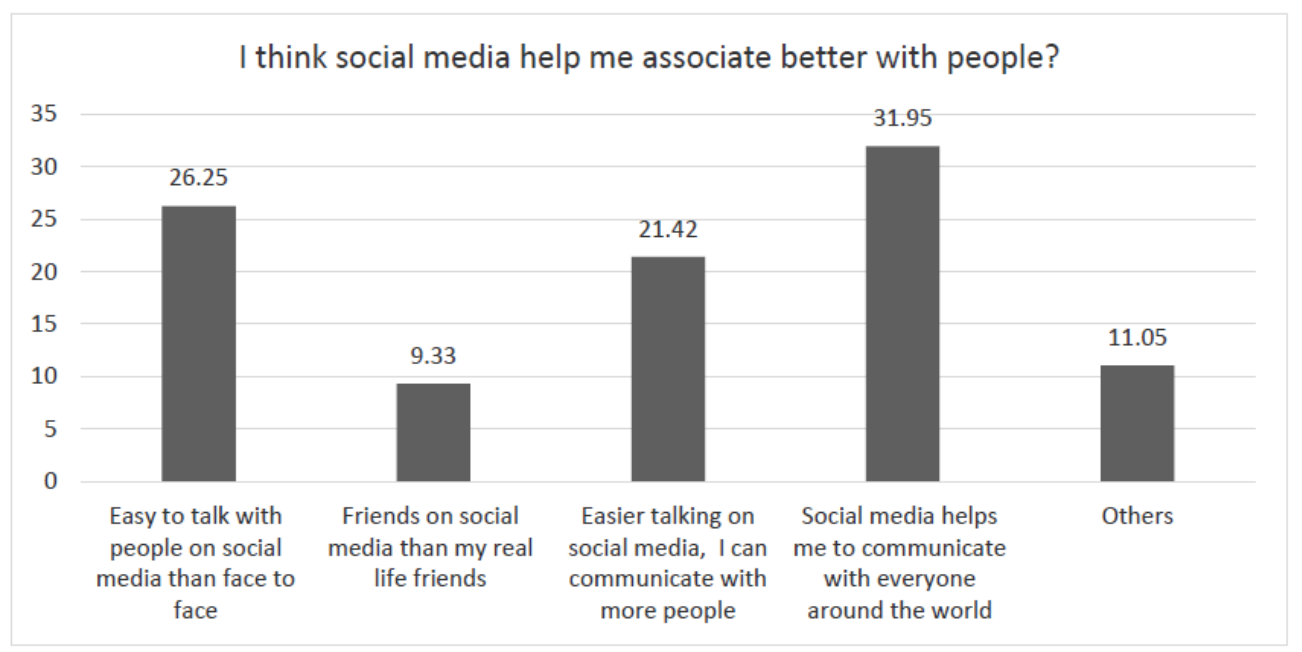

Figure 17. Social media help me associate better with people?

Participants used social media most often to communicate with friends, colleagues and family, as shown in Figure 18. This result is a consistent finding in other studies (Gulatee and Combes, 2018a, 2018b, Combes 2012).

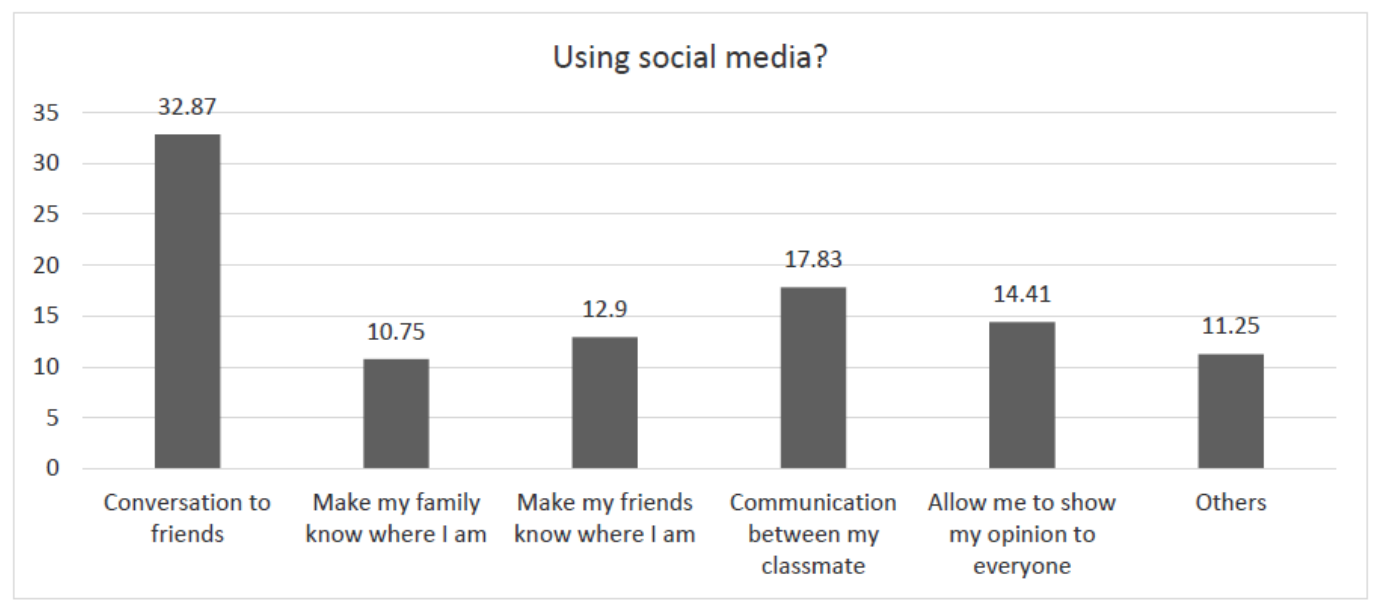

Figure 18. Using social media

\section{The Open-Ended Question}

Figures 19 and 20 indicate that most of the participants were positive in their attitudes to social media, however they were also aware that if they used it in certain ways, there could be a negative impact. Interestingly, participants signaled a reluctance to answer question 18 by using the N/A choice (46\%). This may indicate that they have no opinion or did not consider the positive and negative aspects of social media. In Figure 19, participants appeared to be trying to use social media in a positive way by helping the community. The result indicates that the immediate feedback (like button) was a factor in what they posted. Many of the participants appeared to be posting information to help and empower their communities. The participants in this study were using social media to expand communities' capability and capacity by facilitating the capitalization, development, and evolution of local resources in addressing issues of common interest. The idea of posting because people liked the content indicates that perhaps self-gratification, feelings of empowerment and status are factors for these participants. 


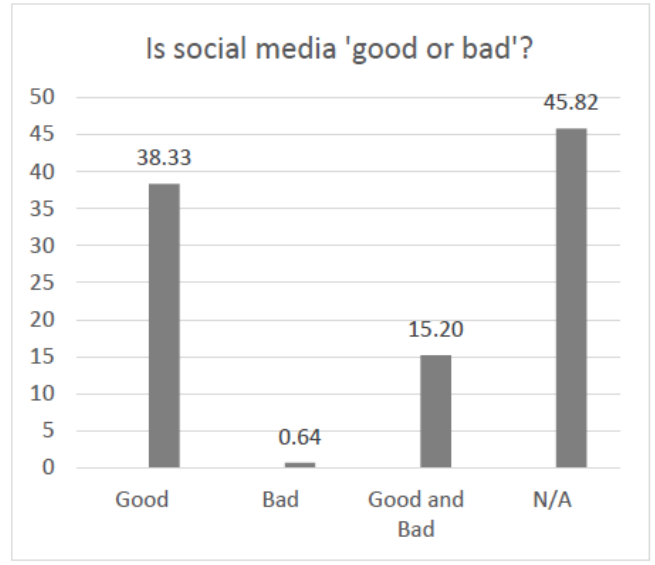

Figure 19. Is social media 'good or bad'?

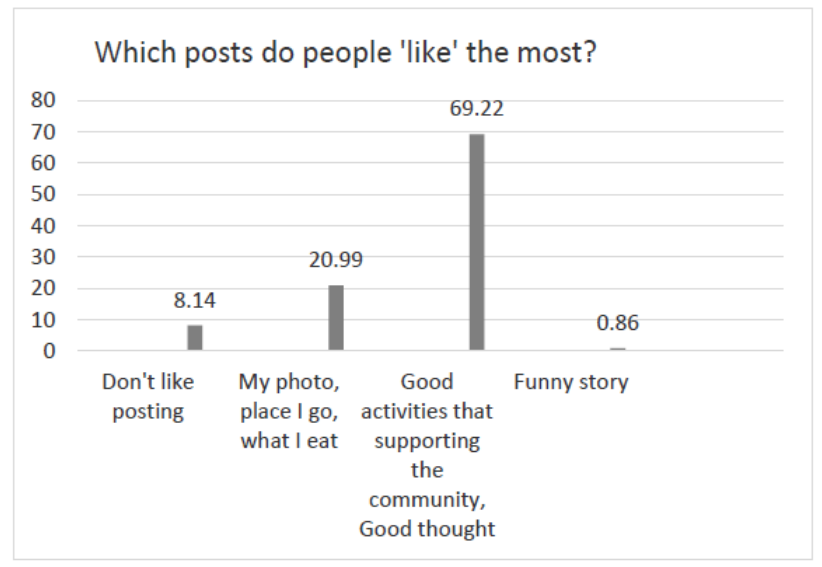

Figure 20. Which posts do people 'like' the most?

\section{Interview}

Volunteer participants (total 33, 29 females and 4 males) also took part in a short semi-structured interview. Responses from the interview questions provided a wealth of qualitative data which was transcribed and coded thematically using both the interview question checklist and probes as a guide to identify and record participant responses (Pickard, 2007; Williamson, 2000). Participants from every faculty across the university were involved in the interviews. Survey participants volunteered for the interview by leaving their email address or phone number for the follow-up interview. The interviews were designed to further explore participants' experiences and gather some in-depth information about how participants felt about their use of social media. Participants recorded their own responses to interview questions. These responses were then classified into categories, coded and analysed. There were five interview questions.

Question 1: Do you use social media in the classroom? Why?

Interestingly, $98 \%$ of the interviewees still thought that using social media during the classroom was not interrupting their study. Examples of responses are shown below:

Stu \#7: 'There is a direct impact on school time because mobile phones are often played during school hours, resulting in decreased interest in school, but it is also often used because it is a convenient communication tool that is easy to use and for research. Easy to find'.

Stu \#11: 'Sometimes it is necessary to use social media for teaching and learning too, such as Facebook created for communication and group work submissions. Which is convenient for editing and being informed at the same time.'

Stu \#15: 'However, the use of social media in the classroom may depend on the teacher's techniques on how to attract the attention of students.'

Stu \#27: 'Because it is easy to communicate and fast.'

Moreover, participants felt that using social media platforms in class was a key tool for connecting and maintaining teaching-learning relationships. They felt that connected classrooms were more interesting than ordinary classrooms, they were more creative, and felt they expanded their learning. Responses to this question were generally positive, however, a consideration may be that participants' responses were influenced by what they thought the interviewer wanted them to say. In a summary of research conducted by Common Sense Media, Knutson (2018) cautions that 'our personal perceptions about social media might not always reflect what our students experience online'. In this research findings included the following:

- Fifty-seven percent (57\%) of participants agreed that social media was distracting from their studies.

- Fifty-four percent (54\%) said that social media often distracted them when they should be listening or engaging with people face-to-face.

- Seventy-two percent (72\%) recognized that the social media platforms were designed to encourage users to spend more time on their devices.

- Many teens felt that social media was a positive rather than a negative in their lives, but also said it wasn't a factor in their use (Knutson, 2018). 
The results from this research closely mirror those found in the Thai research even though location and participants were very different (USA and Thailand).

Question 2: Which social media do you use most and why?

The majority of the interviewees confirmed that Facebook (58\%) is their preferred social media platform. There are 70 million people in Thailand and 50 million Facebook users Lexicon (2019). Participants in this study said they used Facebook for chatting, shopping and commenting on other posts. As found earlier in this research (Figures 5 and 6) most of the participants were using social media on average, at least hourly on every given day. Participants reported they were able to keep track of other people's movements. They also appeared to believe that it was natural to feel curious about what others were doing. While some of the interviewees used social media to compare themselves to others, others used it to be inspired. Tracking the movements and what others were doing also makes it more entertaining. Participants also indicated a strong desire to be educated, informed and entertained via social media.

- Student \#2: 'The most frequently used media is Instagram. It is an app that I use more often than Facebook, because Facebook is too public. Other people can know information or follow our lives. Personally, the Instagram is more personal and makes me more self-assertive.'

- Student \#15: 'Facebook can easily connect with friends. [We can] all each other for free. Can know other people's movements as well. Facebook also has videos to watch, games to play, can buy things as well.'

- Student \#23: 'Facebook, because it knows the news and many people can easily connect.'

- Student \#18: 'Facebook because it's used to contact friends and to study.'

Responses to this question were interesting, because the interviewees often attributed intelligence to the technology (it knows) and appeared to connect or associate themselves (status, ego, feeling confident and positive about self) with the technology.

Question 3: What kind of entertainment do you access with social media?

Participants said they usually use social media for listening to music, reading the news and watching movies (79\%). They also use it for connecting with others and receiving updates $(15 \%)$. They mostly use group pages on social media platforms to catch up with friends, share photos and news. However, online shopping (6\%) is becoming more prevalent. The use of 'Facebook in Thailand takes the place of the daily newspaper, water cooler gossip, gaming platforms, telephones, SMS messages, TV stations, magazines, and pretty much any other form of media you can imagine' (Lexicon, 2019).

- Stu \#3: 'I use Facebook because it's used to contact friends and to study.'

- Stu \#7: 'Friendship and business management, quick contact.'

- Stu \#13: 'Fun when playing games with friends.'

- Stu \#19: 'Receiving news, communication and transactions.'

Question 4: Do you post your photo on social media? Why?

One hundred percent (100\%) of participants said they post their photos on social media. They used their photos to identify themselves to others (friends and unknown people) and to show others how they are living their lives.

- Student \#4: 'To identify myself.'

- Student \#6: 'To show identity and confirm the actual situation from time to time, such as submitting a real situation report.'

- Student \#24: 'In order to convey to the online world that we are like or how to look attractive, because it's not a scam.'

- Student \#26: 'To let other people or people who know us know that this is me, our appearance.'

In this research a hundred percent of the interviewees posted photos of themselves to provide friends and the rest of the world with a continuous record of themselves and what they are doing at any given time. This is a type of narcissistic behaviour (Oxford Dictionary, 2020) where the person posting on the social media platform has an overwhelming need to justify their lives, personal status and appearance. It is a means of establishing and promoting self-identity. This type of egocentric behaviour may become more prevalent during times of social stress and isolation, for example the COVID 19 pandemic.

\section{Q5: What do you think about using social media?}

The interviewees confirmed the findings from the questionnaire and were very positive about using social media. They felt they could use it to benefit the community, to provide up-to-date news during a crisis and provide useful information for the community. They also felt they could use it to prevent and protect themselves by 
communicating real or truth to others. As mentioned in Leong, Pan, Ractham and Kaewkitipong (2015, p.201), 'social media enables individuals to aggregate and exercise their collective strength. By augmenting the voices of powerless individuals or populations, the position of a community escalates, and the capacities and capabilities of the originally dispersed members are synergized, which propels the community forward in its development.'

- Student \# 2: 'Both sides, good and bad. The good side is I know when real news is reported and the bad side is I'm so lazy for searching something in book because I can search in my cell phone.'

- Student \#13: 'There are both good and bad results, if playing to be a good result, such as relaxation.

- Student \# 15: 'If you don't have social media, we may not see things you haven't seen or can't contact people who are far away.'

- Student \#21: 'There are both good and bad sides that we can use.'

- Student \#28: 'Nothing causing the problems, because using social media in the right way. Not illegal and also makes it easier for us to live and communicate.'

Participants in this research were very positive about their use of social media. Issues such as the authenticity of information (authorship, when it was written, bias and opinion), privacy and ownership of information by a third party such as Facebook (Wong, 2019) did not feature in their responses. It is uncertain whether they had a real understanding of these issues or chose to ignore them. Interviewees appeared to feel that the information they posted on social media platforms such as Facebook were not important enough to have cause for concern. There was no indication that they were aware of the concept of 'big data' and how it could be used for ordinary citizens such as themselves (Wong, 2019).

\section{Conclusion}

Social media has now become a ubiquitous part of daily life especially for young people in Thailand who access platforms via their mobile phones (Gulatee \& Combes, 2018b). In this research study it is also important to recognize the use of the social media platform Line as a formal communications channel by the university staff and some student groups. Use of the social media platform in this way formalizes use and gives it a measure of security and credibility for students. This fact may influence how they use and perceive social media platforms.

This research explored our understanding of how social media is being used by young people in Thailand, and how it affects users' attitudes and feelings of self. Participants in the study were using Facebook to connect with friends, family, their peers and the wider community, because it provided an easy-to-use communications tool with people anywhere and anytime. In this study participants were mostly positive about social media, however, some participants acknowledged that social media impaired listening and concentration in the classroom, completing activities in class and personal relationships face-to-face (Lau, 2017). This similarly to Lau, 2017 found that Social media usage in University level potential negative impact include inappropriate in an informal relationship between teachers and students, disrupts formal instruction during class time, and cyberbullying. These results were similar to those reported by Rajesh, et al. (2016) who examined health students' use of Facebook in Nepal. In this research in Thailand perceptions of social media by students were positive rather than negative. Participants also appeared to have a limited understanding of any negative impacts of social media technology such as privacy and access to their personal information.

In this study ninety-eight percent (98\%) of participants were using social media, and eighty percent (80\%) claimed they used it on an hourly basis. Participants also claimed they used Facebook for entertainment, helping the community by posting useful information, promoting themselves and their identity. Some used it to look for information, but this was more about establishing themselves (identity) and promoting and updating their status to others. They felt that positive communication experiences online also made them feel confident about themselves, even if the experiences were very one-sided, that is, they felt good about themselves simply by posting, not necessarily by receiving feedback about the post. Nearly half $(42 \%)$ of the participants allowed everyone to see their status. These young people did not express a high level of concern about third-party access to their data on social media. However, the result is not clear (half and half) about whether participants felt that their use of social media negatively affected their face-to-face communication.

Interestingly, 98\% of the interviewees still thought that using social media during the classroom was not interrupting their study. Some who used social media platforms in class thought it was a key tool for connecting and maintaining teaching-learning relationships, while others felt that connected classrooms were more interesting than ordinary classrooms, they were more creative, and felt the use of technology expanded their learning, However, when questioned further, participants weren't actually using social media for these purposes in class, but rather for personal communication, entertainment, listening to music, reading the news and watching 
movies (79\%). Using social media in class from their perspective was not disruptive, however the teachers may report a different opinion. Other research using Thai students confirmed that social media and Internet use in the classroom were disruptive to learning especially when the use of technology was not integrated into classroom curriculum (Gulatee \& Pongthanoo, 2015).

All participants were using social media to post photographs of themselves and their activities online. They acknowledged that posting photographs were a way of promoting and identifying themselves to others (friends and unknown people). They used social media to build status by showing others how they live their lives. Eighty-five percent of participants (85\%) admitted they posted photos of themselves in an attempt to make themselves look good on social media. Similarly, they felt that posting information that was useful for the community was a way of building self-identity and status, that is, they would be perceived by others as being a 'good person'. This type of behaviour is essentially narcissistic or ego building. Participants were aware that they were posting community information for egotistical reasons rather than altruistic ones. Most admitted they posted such information to make them look good, not because they wanted to assist the community.

Results from Bernstein's research (2019) concluded the disconnection of individuals afforded by the internet, led to frustration which in turn led to feelings of powerlessness, estrangement, loneliness, and anger. However, in this study participants actually felt that social media brought them closer to others and the participants reported positive experiences rather than negative ones when online. These results may also indicate that participants differentiate between the Internet and social media. The term social media indicates that using these tools is a more social activity rather than a formal one. Since the university was using the social media platform Line for formal communications with staff and some student groups, students in this study may perceive social media differently, more acceptable and positive.

Participants in this research felt positive about social media and used it to communicate with friends, family and others. However, they also used it as a vehicle to reach the wider community to provide a life-profile, for self-aggrandisement and to promote themselves to not only trust others, but to the world. This is cause for some concern, because they also did not appear to have a clear understanding about issues such as authority of information and privacy when using social media. More research needs to be conducted in this area to understand why young people feel the need to use social media in this way, the perceived benefits (I feel empowered/confident about myself) and issues that may arise.

\section{References}

Alryalat, M., Alzubi, J., Rana, N., \& Sarma, H., (2016). An empirical study of Facebook adoption among young adults in a Northeastern State of India: Validation of extended technology acceptance model (TAM). Social Media: The Good, the Bad, and the Ugly. I3E 2016. Lecture Notes in Computer Science. p. 206-218. https://doi.org/10.1007/978-3-319-45234-0_19

Bernstein, J. (2019). Alienated, Alone and Angry: What the Digital Revolution really did to us. Retrieved from: https://www.buzzfeednews.com/article/josephbernstein/in-the-2010s-decade-we-became-alienated-by-techn ology

Combes, B. (2012). Tech savvy or tech oriented? Information-seeking behaviour and the Net Generation. PhD Thesis, Curtin University. Retrieved from http://espace.library.curtin.edu.au/webclient/StreamGate?folder_id=0\&dvs=1468295177037 181\&usePid1 $=$ true\&usePid $2=$ true

Fieseler, C., \& Fleck, M. (2013). The pursuit of empowerment through social media: structural social capital dynamcs in CSR-Blogging, Journal of Business Ethics, 188(4), 759-775. https://doi.org/10.1007/s10551-013-1959-9

Gulatee, Y., \& Combes, B. (2018a). Digital refugees? How students in Thailand and Australia seek and use information online. International Journal of the Computer, the Internet and Management (IJCIM), 26(3), 6-14.

Gulatee, Y., \& Combes, B. (2018b). Owning ICT: Student use and ownership of technology. Walailak Journal of Science and Technology, 15(1), 81-94. https://doi.org/10.48048/wjst.2018.2868

Gulatee, Y., \& Pongthanoo, P. (2015). The Usage of Facebook and NPU-ELearning Case study In Faculty of Management and Information Technology, Faculty of Art and Science at Nakhonphanom University. Nakhon Phanom University Journal, 5(3), 89-96.

Gulatee, Y., Pragram, J., \& Combes, B. (2018). Which Tech Will I Use? Trends in Students' Use and Ownership 
of Technology in a Thai University, an Ongoing Study. Journal of ICT Research Application, 12(2), 138-153. https://doi.org/10.5614/itbj.ict.res.appl.2018.12.2.3

Isaranon, Y. (2016). Narcissism and affirmation of the ideal self on social media in Thailand. Goldsmiths, University of London.

Knutson, J. (2018). Understanding your students' social media lives is essential. Retrieved from https://https://www.commonsense.org/education/articles/what-new-research-on-teens-and-social-media-mea ns-for-teachers

Lau, W. F. (2017). Effects of social media usage and social media multitasking on the academic performance of university students. Computers in Human Behavior, 68(2017), 286-291. https://doi.org/10.1016/j.chb.2016.11.043

Leong, C., Pan, S., Ractham, P., \& Kaewkitipong, L. (2015). Ict-enabled community empowerment in crisis response: Social media in Thailand flooding 2011. Journal of the Association for Information Systems, 16(3), 174-212. https://doi.org/10.17705/1jais.00390

Lexicon (2019). Social Media Trends 2019: Part 1 - Facebook in Thailand. Retrieved from https://lexiconthai.com/blog/social-media-trends-2019-facebook-in-thailand/

Liamputtong, P., \& Ezzy, D. (1999). "Qualitative research methods" in "a Health Focus (2nd ed). Melbourne, Oxford, University Press. p. 260-285.

Madden, M., Lenhart, A., Cortesi, S., Gasser, U., Duggan, M., Smith, A., \& Beaton, M. (2013). Teens, Social Media, and Privacy. Retrieved from http://assets.pewresearch.org/wp-content/uploads/sites/14/2013/05/PIP_TeensSocialMediaandPrivacy_PDF.pdf

Makin, S. (2018). Searching for digital technology's effects on well-being. Nature, 563(7733), 140. https://doi.org/10.1038/d41586-018-07503-w

Margaryan, A., Littlejohn, A., Vojt, G. (2011). Are digital natives a myth or reality? University students' use of digital technologies. Computers \& Education, 56(2), 429-440.

https://doi.org/10.1016/j.compedu.2010.09.004

Negroponte, N. (1998). Beyond Digital. Wired, 6(12), 288.

Olsson, T. (2016). Social media and new forms for civic participation. New Media \& Society, 18(10), 2242-2248. https://doi.org/10.1177/1461444816656338

Pickard, A. J. (2007). Research methods in information. Facet Publishing, London, UK. p. 171-182.

Rajesh, K., Dev, K., Sangharshila, B., Keshab, R., Phoolgen, S., Ajit, K., \& Kishor, A. (2016). Facebook use and its effects on the life of health science students in a private medical college of Nepal. Bmc Research Notes, 9(1), 378-378. https://doi.org/10.1186/s13104-016-2186-0

Richtel, M. (2010). Growing up digital, wired for distraction. New York Times. p. 1.

Stastica. (2020a). Facebook - Statistics and facts. Retrieved from https://www.statista.com/topics/751/facebook/

Statista, b. (2020b). Social media user penetration Thailand 2017-2023. Retrieved from https://www.statista.com/statistics/490405/mobile-messaging-user-reach-thailand/

Statistics How To. (2020). What is Convenience Sampling / Accidental Sampling? Retrieved from https://www.statisticshowto.com/convenience-sampling/

Stevenson, M. (2016). Rethinking the participatory web: A history of hotwired's 'new publishing paradigm,' 1994-1997. New Media and Society, 18(7), 1331-1346. https://doi.org/10.1177/1461444814555950

Suksa-ngiam, W., \& Chaiyasoonthorn, W. (2015). The adoption of social media by Thai university students: Multiple group moderating effects. Information Development, 31(1), 69-82. https://doi.org/10.1177/0266666913502800

Wang, Z., Tchernev, M. J., \& Solloway, T. (2012). A dynamic longitudinal examination of social media use, needs, and gratifications among college students. Computers in Human Behavior, 28, 1829-1839. https://doi.org/10.1016/j.chb.2012.05.001

Williamson, K. (2000). Research methods for students, academics and professionals: Information management and systems (2nd ed). Wagga Wagga,NSW: Centre for Information Studies, Charles Stuart University. p. 89-109. 
Wong, J. C. (2019). The Cambridge Analytica scandal changed the world - but it didn't change Facebook. The Guardian. Retrieved from

https://www.theguardian.com/technology/2019/mar/17/the-cambridge-analytica-scandal-changed-the-world -but-it-didnt-change-facebook

\section{Copyrights}

Copyright for this article is retained by the author(s), with first publication rights granted to the journal.

This is an open-access article distributed under the terms and conditions of the Creative Commons Attribution license (http://creativecommons.org/licenses/by/4.0/). 